\title{
Effect of Intrauterine Ethanol Exposure on Fetal Lung Growth
}

\author{
LAURA S. INSELMAN, M.D., STANLEY E. FISHER, M.D., HYACINTH SPENCER, M.S., AND \\ MARK ATKINSON, M.S. \\ Pulmonary and Gastroenterology Divisions, Department of Pediatrics, North Shore University Hospital, \\ Manhasset, New York, and Department of Pediatrics, Cornell University Medical College, New York, New York
}

\begin{abstract}
Lung weight, DNA, RNA, protein, and total body weight were analyzed in fetuses from 14 pregnant Sprague-Dawley rats fed a nutritionally complete liquid diet containing $v / v 6 \%$ ethanol (ethanol group). Each ethanol rat was matched with an isocalorically pair-fed animal (control group) who received the same liquid diet with carbohydrate substituted for ethanol. The rats were killed on day 20 of gestation. The mean maternal blood ethanol concentration at $0700 \mathrm{~h}$ on day 20 was $170 \pm 22$ (SE) $\mathrm{mg} / \mathrm{dl}$. Compared to controls, ethanol fetuses had reduced body weight $(21 \%)$, lung dry weight $(39 \%)$, lung wet weight/body weight ratio $(\mathbf{1 0} \%)$, DNA $(21 \%)$, RNA $(25 \%)$, protein $(28 \%)$, and protein/DNA ratio $(8 \%)(p<$ $0.05)$. The results indicate that prenatal ethanol exposure inhibits cellular growth in the fetal lung, resulting in hypoplastic lungs which have fewer and smaller cells. The effect on the lung appears to be greater than on the body as a whole. These hypoplastic lungs may be predisposed to the development of pulmonary disease and may explain observations of more frequent and severe lower respiratory infections in children with prenatal ethanol exposure. (Pediatr Res 19: 12-14, 1985)
\end{abstract}

\section{Abbreviation}

FAS, fetal alcohol syndrome

Prenatal ethanol exposure results in a spectrum of growth disturbances known as the FAS and includes intrauterine and postnatal growth retardation, facial dysmorphogenesis, and CNS dysfunction (30). Hypoplasia and malformations of different organs are described both clinically and experimentally in the FAS $(8,15,23,30)$.

Children with the FAS have an increased frequency and severity of lower respiratory tract infections, which have been previously attributed to immunologic deficiencies induced prenatally by ethanol (19). In addition, decreased production of lung surfactant, decreased activity of pulmonary alveolar macrophages and cilia, and impaired migration of polymorphonuclear leukocytes to the lung occur with ethanol exposure in the adult $(2,13$, 14, 31).

Received February 10, 1984; accepted July 11, 1984.

Send correspondence and reprint requests to Laura S. Inselman, M.D., Department of Pediatrics, North Shore University Hospital, 300 Community Drive, Manhasset, NY 11030.

Supported in part by a grant RO1-HD 17375 from the NICHD. S.E.F. is the recipient of a Research Scientist Development Award K02 AA00074 from the NIAAA.
Ethanol may also affect the growth and development of the lung. Since lung growth is characterized by the formation of all pulmonary airways and air spaces during gestation $(18,22)$, intrauterine ethanol exposure may alter prenatal lung growth and predispose the lung to the future development of disease. Therefore, the effect of chronic prenatal ethanol ingestion on fetal lung growth was studied in rats.

\section{MATERIALS AND METHODS}

Eight mature female Sprague-Dawley rats (ethanol group) were acclimated over 10 days to a nutritionally complete liquid diet, modified for pregnancy with additional vitamins and minerals (Lieber-DeCarli; BioServ Inc, Frenchtown, NJ). The ethanol diet contained $\mathrm{v} / \mathrm{v} 2 \%$ ethanol for 3 days, $4 \%$ for 3 additional days, and $6 \%$ thereafter. Each ethanol rat was matched with an isocalorically pair-fed animal (control group) who received the same liquid diet with carbohydrate substituted for ethanol. Both liquid diets have a caloric density of $1 \mathrm{cal} / \mathrm{ml}$ with 18 and $35 \%$ of the calories provided by protein and fat, respectively. Ethanol provides approximately $35 \%$ of the calories in the $6 \%$ ethanol diet.

During the mating period the liquid diets were discontinued and the rats were fed Purina Chow (Ralston Purina no. 5001, St. Louis, MO) ad libitum. When pregnant, as ascertained by vaginal smear, they were returned to their respective liquid diets.

The day the vaginal plug was first observed was designated as day 0 of pregnancy. At $0700 \mathrm{~h}$ on pregnancy day 20 , blood ethanol concentrations were determined by the alcohol dehydrogenase method (Ethyl Alcohol Stat-Pak; Calbiochem-Behring, La Jolla, CA) (5). The rats in both groups were then weighed and killed by cervical dislocation. To eliminate any possible diurnal variations in cellular response, all animals were killed between 9.00 and $11.00 \mathrm{~h}(7)$.

Gross abnormalities and number of fetal resorptions were noted. The fetuses were removed, weighed, and immediately placed on ice. Their lungs were dissected, weighed, and immediately frozen for biochemical analyses. Since individual fetal lungs were too small for nucleic acid analysis, three to seven lungs from each litter were pooled and homogenized. Lung tissue nucleic acids were extracted by a modified Schmidt-Thannhauser procedure (26). DNA and RNA were determined by UV absorption at 268 and $260 \mathrm{~nm}$, respectively. Lung tissue protein was determined by the Lowry method (24). DNA, RNA, and protein standards were obtained from the Sigma Chemical Company (St. Louis, MO).

Since all fetal lungs from these eight pairs of rats were used for biochemical analyses, the effect of ethanol on the fetal lung dry weight/wet weight ratio was determined in fetuses from an additional six pregnant Sprague-Dawley rats who were fed the $6 \%$ ethanol diet. Isocalorically pair-fed matched pregnant controls received the carbohydrate-substituted liquid diet. Maternal 
blood ethanol levels were obtained at $07.00 \mathrm{~h}$, and the rats were killed by a combination of pentobarbital and ether. The fetuses and their lungs were individually weighed. Lungs from each of these fetal litters were pooled and dried to constant weight at $60^{\circ}$ C.

Since there was no difference in ethanol intake between the two groups of ethanol-fed mothers, their data for weight gain, blood ethanol levels, and litter size were combined. Similarly, fetal data for body and lung weights were combined.

A mean value for each measurement was obtained per litter. Statistical significance of the data was assessed by the paired $t$ test (3) in which each ethanol-treated litter was matched with its isocalorically pair-fed control. Results are expressed as means \pm $\mathrm{SE}$ and are considered significant for $p<0.05$.

\section{RESULTS}

There was no difference in maternal weight gain between the ethanol ( $83 \pm 8 \mathrm{~g}, n=14)$ and control ( $79 \pm 5 \mathrm{~g}, n=14)$ groups. Litter size was similar, with $11.6 \pm 0.8$ ethanol fetuses/litter $(n$ $=14)$ and $12.1 \pm 0.7$ control fetuses/litter $(n=14)$. Maternal daily ethanol intake was $11.6 \pm 0.3 \mathrm{~g} / \mathrm{kg}(n=14)$, and the maternal blood ethanol concentration was $170 \pm 22 \mathrm{mg} / \mathrm{dl}(n=$ 9).

Three fetal reabsorptions and one stillbirth occurred in two ethanol dams, and one control dam had a reabsorption. Gross abnormalities were absent in the fetuses. There was no gross evidence of infection in the maternal and fetal lungs, and all lungs at the termination of the study were uniformly inflated and homogeneously pink in color.

Compared to controls, the ethanol fetuses had significant reductions in body weight $(21 \%)$ (Table 1$)$. Not only were lung wet and dry weights significantly diminished by 29 and $39 \%$, respectively, but the lung wet weight/body weight ratio was also significantly lower by $10 \%$ (Table 1), indicating the presence of smaller lungs. Significant decreases in DNA $(21 \%)$, RNA $(25 \%)$, protein $(28 \%)$, and the protein/DNA ratio $(8 \%)$ were also present in the ethanol fetuses as compared to the control fetuses (Fig. 1 and 2). The RNA/DNA ratio remained unchanged. This indicates inhibition of cellular growth as measured by DNA content, which reflects cell number, and by the protein/DNA ratio, which reflects cell size (18).

\section{DISCUSSION}

The results of these studies demonstrate that chronic exposure to high doses of ethanol during gestation alters the growth and development of the fetal lung. Diminished lung cell number and size characterize these hypoplastic lungs. Intrauterine ethanol exposure inhibits DNA and protein synthesis in the fetal lung, a finding consistent with observations of inhibition of DNA and protein synthesis in other organs $(11,15-16)$.

Ethanol exposure in this model as well as in the human occurs during the early stages of lung development when the branching pattern of the pulmonary airways is forming (18). Since prenatal ethanol exposure inhibits cellular growth in the lung, it is possible that ethanol alters the branching pattern, resulting in diminished numbers of airways and subsequently diminished numbers of

Table 1. Fetal body and lung weights (means \pm SE.)

\begin{tabular}{lcl}
\hline & Ethanol group & Control group \\
\hline Body wt/fetus $(\mathrm{g})$ & $3.04 \pm 0.18^{* *}(14)$ & $3.87 \pm 0.20(14)$ \\
Lung wet wt/fetus $(\mathrm{mg})$ & $69.2 \pm 5.9^{* *}(14)$ & $97.8 \pm 5.5(14)$ \\
Lung wet wt/body wt $\left(\times 10^{-2}\right)$ & $2.28 \pm 0.09^{*}(14)$ & $2.54 \pm 0.09(14)$ \\
Lung dry wt/fetus $(\mathrm{mg})$ & $7.0 \pm 0.4^{* *}(6)$ & $11.4 \pm 0.4(6)$ \\
Lung dry wt/wet wt $\left(\times 10^{-2}\right)$ & $13.2 \pm 0.3(6)$ & $13.0 \pm 0.6(6)$ \\
\hline
\end{tabular}

Numbers in parentheses represent number of litters.

$* p<0.05$.

$* * p<0.01$
DNA

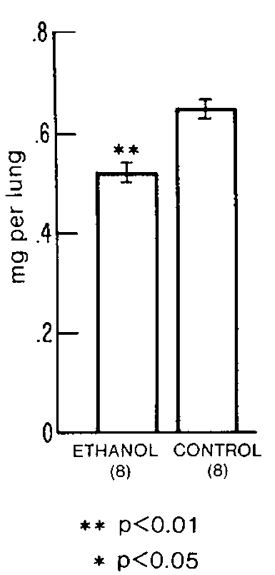

PROTEIN

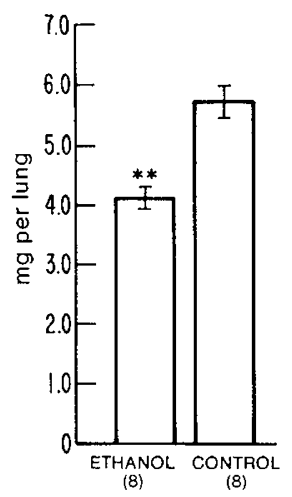

PROTEIN / DNA

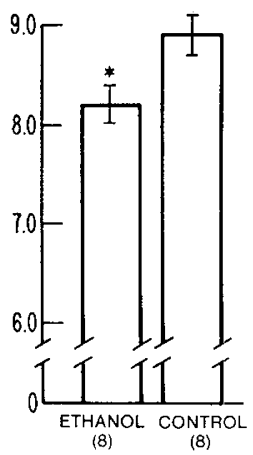

Fig. 1. Comparison of cell number (DNA content) and cell size (protein/DNA ratio) in ethanol-exposed and control fetal rat lungs. Means $\pm \mathrm{SE}$ are shown. Numbers in parentheses represent number of litters.

RNA

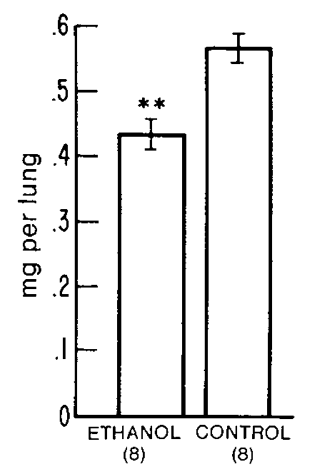

RNA / DNA

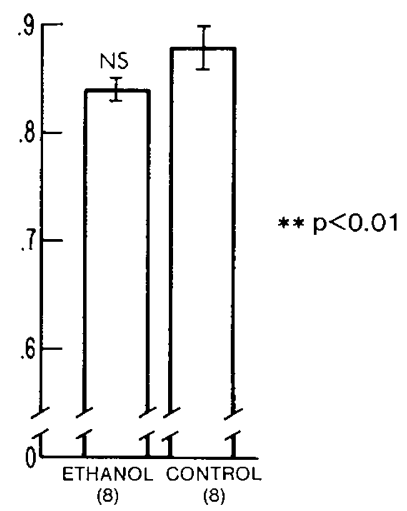

Fig. 2. Comparison of RNA content and RNA/DNA ratio in ethanolexposed and control fetal rat lungs. Means $\pm S E$ are shown. Numbers in parentheses represent number of litters.

alveoli (18). However, morphologic studies are necessary to delineate further the inhibitory role of ethanol on fetal lung growth.

The model used in the present study results in maternal blood ethanol concentrations which are comparable to human levels during chronic heavy drinking. Unlike other models of chronic ethanol consumption during pregnancy $(1,15)$, maternal weight gain and litter size are not altered and therefore do not contribute to the observed fetal differences. With the use of pair-fed controls, our results are independent of maternal nutrient intake. Yet, intrauterine growth retardation does occur.

The etiology for hypoplastic lung growth with chronic prenatal ethanol exposure is unknown. Several mechanisms might be implicated and include direct toxicity of ethanol or its metabolites $(4,11,16,28)$, impaired placental transport of nutrients $(10$, 27 ) or oxygen $(20,25,27)$, hypoxia-induced pulmonary vasoconstriction potentiated by ethanol $(9,12,17)$, alterations in activities of pulmonary chemical mediators $(6,18,21,29)$, and diminished surfactant synthesis (31). Regardless of the mechanism of action, the reduction in lung size relative to body weight indicates that the lung is particularly susceptible to intrauterine ethanol exposure.

Pulmonary disorders have not been previously considered to be a manifestation of the FAS. However, the present experiments indicate that the lung is a target organ for ethanol-induced 
alterations in cellular and organ growth. Additional studies are necessary to evaluate the etiology and mechanisms of ethanolinduced prenatal pulmonary hypoplasia. The present investigations have particular clinical importance in the pediatric population who may be exposed to environmental toxins before birth and may have significance in the prevention of pulmonary disease in this age group.

\section{REFERENCES}

1. Abel EL, Dintcheff BA 1978 Effects of prenatal alcohol exposure on growth and development in rats. J Pharmacol Exp Ther 207:916

2. Astry CL, Warr GA, Jakab GJ 1983 Impairment of polymorphonuclear leukocyte immigration as a mechanism of alcohol-induced suppression of pulmonary antibacterial defenses. Am Rev Respir Dis 128:113

3. Bahn AK 1972 Basic Medical Statistics. New York, Grune and Stratton, Inc.

4. Bernstein J 1982 The role of the lung in the metabolism of ethanol. Res Commun Chem Pathol Pharmacol 38:43

5. Bonnichsen RK, Theorell H 1951 An enzymatic method for the microdetermination of ethanol. Scand $\mathbf{J}$ Clin Lab Invest 3:58

6. Brigham KL, Ogletree M, Snapper J, Hinson J, Parker R 1983 Prostaglandins and lung injury. Chest 83:70S

7. Das RM, Jain M, Thurlbeck WM 1979 Diurnal variation of deoxyribonucleic acid synthesis in murine alveolar wall cells and airway epithelial cells. Am Rev Respir Dis 119:81

8. DeBeukelaer MM, Randall CL, Stroud DR 1977 Renal anomalies in the fetal alcohol syndrome. J Pediatr 91:759

9. Doekel RC, Weir EK, Looga R, Grover RF, Reeves JT 1978 Potentiation of hypoxic pulmonary vasoconstriction by ethyl alcohol in dogs. J Appl Physiol 44:76

10. Fisher SE Atkinson M, Jacobson S, Sehgal P, Burnap J, Holmes E, Teichberg S, Kahn E, Jaffe R, Van Thiel DH 1983 Selective fetal malnutrition: the effect of in vivo ethanol exposure upon in vitro placental uptake of amino acids in the non-human primate. Pediatr Res 17:704

11. Fisher SE, Barnicle MA, Steis B, Holzman I, Van Thiel DH 1981 Effects of acute ethanol exposure upon in vivo leucine uptake and protein synthesis in the fetal rat. Pediatr Res 15:335

12. Fishman AP 1976 Hypoxia on the pulmonary circulation. How and where it acts. Circ Res 38:221

13. Green GM 1968 Pulmonary clearance of infectious agents. Ann Rev Med $19: 315$
14. Guarneri JJ, Laurenzi GA 1968 Effect of alcohol on the mobilization of alveolar macrophages. J Lab Clin Med 72:40

15. Henderson GI, Hoyumpa AM, Jr, McClain C, Schenker S 1979 The effects of chronic and acute alcohol administration on fetal development in the rat. Alcoholism Clin Exp Res 3:99

16. Henderson GI, Patwardhan RV, Hoyumpa AM, Jr, Schenker S 1981 Fetal alcohol syndrome: overview of pathogenesis. Neurobehav Toxicol Teratol 3:73

17. Hislop A, Reid L 1976 New findings in pulmonary arteries of rats with hypoxiainduced pulmonary hypertension. Br J Exp Pathol 57:542

18. Inselman LS, Mellins RB 1981 Growth and development of the lung. J Pediatr 98:1

19. Johnson S, Knight R, Marmer DJ, Steele RW 1981 Immune deficiency in fetal alcohol syndrome. Pediatr Res 15:908

20. Jones PJH, Leichter J, Lee M 1981 Placental blood flow in rats fed alcohol before and during gestation. Life Sci 29:1153

21. Keane PM, Kay JM, Suyama KL, Gauthier D, Andrew K 1982 Lung angiotensin converting enzyme activity in rats with pulmonary hypertension. Thorax 37:198

22. Langston C, Kida K, Reed M, Thurlbeck WM 1984 Human lung growth in late gestation and in the neonate. Am Rev Respir Dis 129:607

23. Löser H, Majewski F 1977 Type and frequency of cardiac defects in embryofetal alcohol syndrome. Report of 16 cases. Br Heart J 39:1374

24. Lowry OH, Rosebrough NJ, Farr AL, Randall RJ 1951 Protein measurement with the folin phenol reagent. J Biol Chem 193:265

25. Mukherjee AB, Hodgen GD 1982 Maternal ethanol exposure induces transient impairment of umbilical circulation and fetal hypoxia in monkeys. Science 218:700

26. Munro HN, Fleck A 1966 The determination of nucleic acids. Meth Biochem Anal 14:113

27. Patwardhan RV, Schenker S, Henderson GI, Abou-Mourad NN, Hoyumpa AM, Jr 1981 Short-term and long-term ethanol administration inhibits the placental uptake and transport of valine in rats. J Lab Clin Med 98:251

28. Rutstein DD Nickerson RJ, Vernon AA, Kishore $P$, Veech RL, Felver ME Needham LL, Thacker SB 1983 2,3-Butanediol: an unusual metabolite in the serum of severely alcoholic men during acute intoxication. Lancet $2: 534$

29. Stalcup SA, Lipset JS, Mellins RB 1980 Modulation of converting enzyme activity by hypoxia and its physiological effects. In: Metabolic Activities of the Lung. CIBA Foundation Symposium 78 (new series). New York, Excerpta Medica pp 293-311

30. Streissguth ÄP, Landesman-Dwyer S, Martin JC, Smith DW 1980 Teratogenic effects of alcohol in humans and laboratory animals. Science 209:353

31. Wagner M, Heinemann HO 1975 Effect of ethanol on phospholipid metabolism by the rat lung. Am J Physiol 229:1316 